\title{
Perceptions of Directly Targeting SEL Learning Skills in Public Education
}

\author{
DeShanna Reed, Kaci Deauquier Sheridan \\ University of Houston, Houston, TX, USA \\ Email: deshannak79@gmail.com, ksheridan@gmail.com
}

How to cite this paper: Reed, D., \& Sheridan, K. D. (2021). Perceptions of Directly Targeting SEL Learning Skills in Public Education. Creative Education, 12, 2765-2779. https://doi.org/10.4236/ce.2021.1211204

Received: October 11, 2021

Accepted: November 27, 2021

Published: November 30, 2021

Copyright $\odot 2021$ by author(s) and Scientific Research Publishing Inc. This work is licensed under the Creative Commons Attribution International License (CC BY 4.0).

http://creativecommons.org/licenses/by/4.0/ (c) (i) Open Access

\begin{abstract}
Social and emotional learning (SEL) has garnered increasing attention across education over the last decade. The continual decline in the mental health of students in PK-12 education, in light of the widespread impact of the COVID-19 pandemic, has forced school districts nationwide to re-examine their reliance on student performance data as measured by high-stakes standardized tests. This is particularly true for students in underserved populations who were among the greatest impacted. Many schools in districts across the nation have begun to examine SEL and its impact on student performance. Despite numerous studies highlighting the benefits of SEL programming, school administrators and teachers still struggle with implementing the practices in their classrooms and campuses. This research sought to identify current perceptions of SEL held by public school practitioners. Practitioner understanding of SEL was based on a ranking of key SEL skills needed for student success. Perceptions regarding potential barriers and with whom the responsibility for directly targeting SEL skills lies were also examined. A non-experimental survey design was utilized to compare data between two groups of public education practitioners: teachers and administrative staff. Overall, it was determined that educators, for the most part, agree on what SEL skills make a student successful; however, reported barriers to implementation and designation of the individual responsible for directly teaching SEL skills differed between the two groups.
\end{abstract}

\section{Keywords}

Social and Emotional Learning (SEL), Public Education

\section{Introduction}

High-stakes testing, social media, changing standards, and media saturation are 
just a few of the ever-changing goalposts that contribute to the immense pressure students in K-12 experience (Bridgeland, Bruce, \& Hariharan, 2013; Jones \& Doolittle, 2017). The increase in school violence incidents, along with the decline in the mental health of students in PK-12 education, has brought increased attention to SEL learning (SEL). School districts nationwide have been forced to re-examine their approach to meeting the needs of all students (Twenge, 2009). Reliance on student performance data as measured by high-stakes standardized tests has proven to be an ineffective predictor of student success, especially for students in underserved populations (Shriver \& Weissberg, 2020). Factoring in the unprecedented impact of the COVID-19 pandemic and increased awareness of social injustice issues toward people of color in America, educators and their students alike are faced with more complex challenges on the horizon. It is for these and other innumerable reasons that educators find it difficult to ensure that the emotional needs of students are met while simultaneously guiding their students to meet or exceed the expected academic standards (Yoshikawa, Aber, $\&$ Beardslee, 2012). The prescribed solution came in from a well-known psychological phenomenon: SEL learning (SEL).

SEL programs have been proven effective in helping students improve their social, emotional, and academic lives (Bridgeland, et al., 2013; Bierman, Coie, Dodge, Greenberg, Lochman, \& McMahon, 2010; Durlak, Weissberg, Dymnicki, Taylor, \& Schellinger, 2011; Greenberg, Domitrovich, Weissberg, \& Durlak, 2017; McBride, Chung, \& Robertson, 2016) and, as a result, also improve academic performance, especially when implemented by campus staff (Durlak, Weissberg, Dymnicki, Taylor, \& Schellinger, 2011). Many previous studies have highlighted the need for, and benefits of, increased focus on SEL learning in classrooms and within schools (Durlak et al., 2011; Smith \& Low, 2013). There has been much debate, however, about what school-wide programs improve climate and culture and effectively make the most impact on student behavior (Atwell \& Bridgeland, 2019; Cohen, McCabe, Michell, \& Pickeral, 2009; McBride, Chung, \& Robertson, 2016).

Schoolwide SEL programs can be beneficial to a large group of students yielding short-term and long-term gains for the individual, teachers, school, community, and workforce (Elias, 2006, Payton, Weissberg, Durlak, Dymnicki, Taylor, Schellinger, \& Pachan, 2000). Schoolwide interventions are among the most effective approaches to improve students' academic and behavioral skills (Bridgeland, Bruce, \& Hariharan, 2013; Durlak et al., 2011; Greenberg, et al., 2017). Greenberg, Domitrovich, Weissberg, and Durlak, 2017 found that $95 \%$ of teachers surveyed believed that SEL skills were teachable in the school setting. Bridgeland, Bruce, and Hariharan, 2013 found that $81 \%$ of teachers believe that teaching SEL skills are necessary for schools; however, less than half (44\%) say that these skills are being targeted, taught, or addressed in a programmatic school-wide fashion. In this same study, more than $80 \%$ of teachers agreed that these skills have a positive effect on workforce readiness, attendance, climate, 
and life success (Bridgeland, et al., 2013). Even with the overwhelming evidence that these programs work, improve the lives of children, and help them be more successful in and out of school, school-wide implementation is rarely done consistently and with fidelity (Durlak et al., 2011). If so many educators agree that SEL skills are important to student success (Schonert-Reichi, 2017), why are so few secondary campuses using proactive approaches to address problem behavior through programs to teach SEL skills?

Many schools in districts across the nation have begun to examine SEL learning (SEL) and its impact on student performance. Even though research has successfully argued the benefits of SEL programming, school administrators have still been reluctant to latch on to the idea (Atwell \& Bridgeland, 2019). Administrators argue that programs are cost and time-prohibitive and require a great deal of planning time that they do not have (Lee, 2016). Research indicates that campuses are implementing SEL programs in an ad hoc fashion (small group or individual students) or on an individual teacher basis (Bridgeland et al., 2013; McBride, Chung, \& Robertson, 2016). Some campus leaders have reported that they begin to utilize school-wide SEL programs initially, only to later prioritize other academic programs (Bridgeland et al., 2013; Greenberg et al., 2017).

Educators, teachers, and administrators alike, have indicated that there are many barriers to school-wide implementation (Atwell \& Bridgeland, 2019). Challenges cited include time (Anyon, Nicotera, \& Veeh, 2016; Bridgeland et al., 2013), inconsistency with staff members' beliefs about behavior change and management, teacher and administrator buy-in, and training and support systems (Anyon, Nicotera, \& Veeh, 2016). Secondary campuses have the increased challenges of personnel available, high stakes standards, and poorly developed climates to support the implementation of these types of programs. At the secondary level, many educators believe that students "should" understand or know how to behave and believe that discipline should be designed to punish rather than teach SEL skills to prepare them for the world outside of school (Anyon, Nicotera, \& Veeh, 2016). These factors, coupled with increasing demands on educators, often lead to SEL programs, while important, to be pushed aside for other initiatives. Meanwhile, school leaders who have implemented the programs argue that universal SEL supports are worth the cost upfront to reap long-term gains (Greenberg, Domitrovich, Weissberg, \& Durlak, 2017).

Federal legislation and funding allocated to education agencies as a result of the Every Student Succeeds Act (2015) stipulated that the onus of addressing school mental health and academic performance was at the district and campus levels within each state (Hess, 2017). As a result, state and local education agencies mandated that schools identify some means of addressing the SEL of their students (Hess, 2017). While many districts nationwide have adopted some form of SEL programming, most programs are expensive, require significant training, and do not always meet the unique needs of students (Bailey, Stickle, et al., 2019). In light of these facts, the researchers sought to deduce perceptions and 
understandings of SEL held by current public school practitioners, potential barriers to SEL implementation, and with whom the responsibility for directly targeting SEL skills lies.

The purpose of this study was to identify perceptions and understandings of SEL in PK-12 public education held by classroom teachers and administrative staff. Moreover, the researchers were interested in determining how understandings held by each group impacted the implementation of SEL programs in classrooms. Determining these understanding and perceptions may serve to reveal practitioner needs as well as potential barriers to SEL implementation experienced across districts nationwide. To identify perceptions and determine understandings, the researchers developed the three research questions below with the goal of examining the differences in responses between teacher and administrative staff responses for each question:

1) Do teaching staff and administrators have a shared understanding of what "SEL learning" means, and which SEL skills are most important for student success?

2) What perceived barriers are reported in each group that prevents directly targeting SEL learning skills?

3) Who do teacher and administrative staff perceive as responsible for providing direct instruction for students' SEL learning?

Understanding the beliefs of campus personnel is crucial to addressing the challenges of implementation. Only then, will we be able to move forward and design programs that can be implemented with fidelity so that all students can be successful academically, socially, and emotionally.

\section{Definitions}

- Social and emotional learning (SEL): the process of developing skills, including self-management, self-awareness, relationship skills, social awareness, and responsible decision making by children and adults (Bridgeland et al., 2013).

- Social and emotional learning programs: programmatic approaches to implementation of programs that directly instruct all students on campus in SEL skills (Bridgeland et al., 2013; Greenberg et al., 2017).

- School-wide SEL programs - SEL intervention programs that are appropriate for the general student body without any identified behavioral or emotional challenges (Payton et al., 2000).

- Education practitioners are not limited solely to classroom teachers. The term includes all educators (core subjects and electives), support staff, school counselors, academic and behavioral interventionists, instructional coaches, and both campus and district-level administrators.

\section{Research Design}

A non-experimental survey design utilizing a uniquely designed survey was completed to explore the aforementioned research questions. A researcher- designed survey was vetted and provided to participants electronically. Survey methodology has been shown to increase the ability to recruit a larger number of 
participants, widen geographical options, and increase participation (Ponto, 2015). This methodology was chosen due to the large sample size targeted and the fact that survey research allowed flexibility for the inclusion of participants.

\section{Population}

For this study, the population of public educators working on PK-12 campuses was targeted. Other inclusion criteria included that individuals had to be over the age of 18 and teachers, staff, support staff, campus-level teacher leaders, or administrators in public education within the United States. Individuals who did not meet the above criteria were not included in the analysis of data. There were no financial or other benefits from participating in the study. Subjects understood that they were merely contributing to the research in this area.

\section{Sample}

A total of 105 individuals completed the survey, 53 who identified as teaching staff, and 52 who identified as district or campus level staff administration/leadership. Participants were largely female $(\mathrm{n}=97), 7$ males, and 1 non-binary individual. Those who completed the survey were also largely white/Caucasian $(\mathrm{n}=81)$ with smaller black/African American $(\mathrm{n}=12)$ and Hispanic/Latin X $(n=11)$ samples. One person identified as biracial. The survey was completed by participants from all over the United States. Most participants came from the Southwest region $(n=83)$ while smaller numbers participated from the Southeast $(n=10)$, northeast $(n=7)$, and the Western $(n=5)$ regions of the United States. Experience in public education varied between participants; however, most participants had 4-6 years of experience $(n=33)$ (see Figure 1).

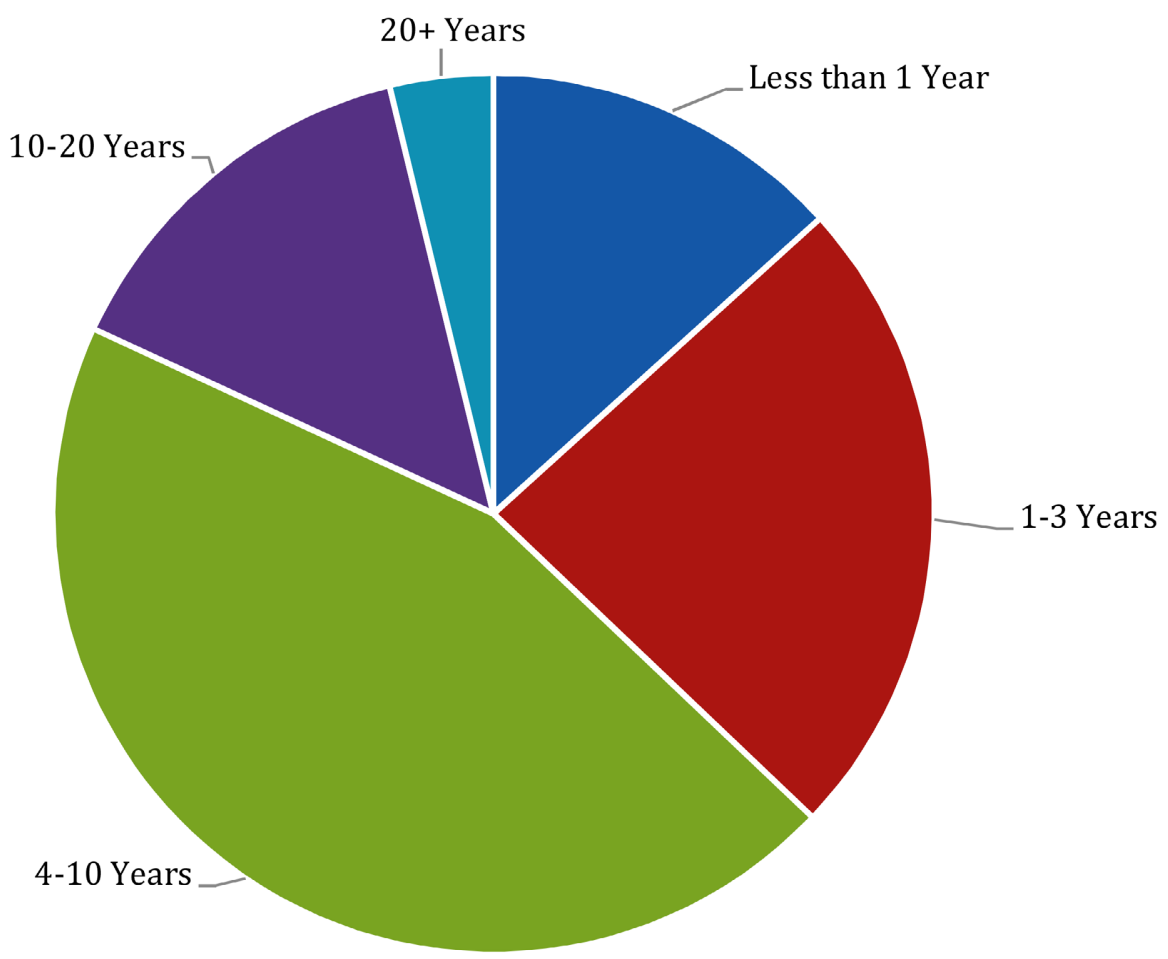

Figure 1. Participant years of experience, percentage. 
This study utilized non-probability convenient sampling methods. This sampling method was chosen due to the exploratory nature of the work, the simplicity, and the cost-effective nature of this method. This study sought to test a theory that a barrier to implementation of SEL programs may be due to a lack of understanding and confidence with the material; however, there was very little existing research to support the theory. Ethically the researchers felt it prudent to approach sampling in this manner to determine if the problem was worth future investigation (Salkind, 2014).

\section{Instrumentation}

A uniquely developed survey tool was utilized to measure the perception of SEL and other factors that impede implementation. Phase one of instrumentation development involved researching and evaluating a multitude of SEL skills and training surveys; however, none of these tools directly reported on or determined the level of competency the practitioner felt with the content succinctly and concisely. Once a draft of the survey has developed a panel of experts was used to vet it. A focus group of 6 individuals currently working in PK-12 public education at all different levels was asked to play a part in developing the survey instrument. Expert opinions helped to mitigate the potential for bias in the instrument (Ponto, 2015). Content validity was established through vetting by this panel of experts (Salkind, 2014). The final survey instrument consisted of 19 questions that sought to determine participants' experiences and comfort with SEL learning. Questions were developed to specifically target each of the three research questions to fully comprehend educator beliefs and experiences.

\section{Data Collection Procedure and Treatment of the Data}

A Google Form survey was created to collect anonymous responses to a combination of multiple-choice, checkbox, and Likert scale questions. Participants' demographic information collected included background, experience, location (region), and information regarding barriers to and understanding of SEL, and responsibility for implementation. All survey data were collected and compiled in a password-protected database and organized based on responses to questions. Convenient sampling measures were employed using online forums such as social media (i.e. Facebook, LinkedIn, and Twitter) that targeted specific groups with members in public education. A short letter of introduction and informed consent was provided to participants at the beginning of the survey. The survey was open for 2 months to participants to ensure the highest number of responses possible. After that time, the survey link was no longer "live" and was removed from internet forums.

\section{Results}

A total of 106 individuals consented to participate in the study and completed the research survey. Based on the variety of positions held by participants, it was determined that dividing participants into two distinct groups allowed for deeper examination and understanding of the similarities and differences in res- 
ponses. Data for the teaching staff and other administrative staff are reported in the tables and figures below. Bivariate analyses of central tendency (mean, median, and mode) between groups were applied for each research question.

Research question one sought to understand whether teaching staff and administrators have a shared understanding of the definition of "SEL learning (SEL)" as well as which SEL skills they deemed most important for student success. Almost all (98\%) of the participants were able to correctly identify the definition for SEL; however, the survey went a bit deeper, in that it sought to understand what specific skills educators felt were most important to SEL. Those in the administrative group ranked the SEL competencies they felt most important for student success as empathy (18.82\%), emotional self-control (18.82\%), personal responsibility $(12.94 \%)$, perseverance $(8.24 \%)$, a tie between positive self-talk and getting along well with others (7.06\%), and goal setting (4.71\%). Those in the teaching staff group indicated that the following skills were the most valuable SEL competencies for student's success as empathy (20.24\%), emotional self-control (11.90\%), personal responsibility (11.31\%), a tie for trust and perseverance (7.74\%), and positive self-talk (7.14\%). Sixteen preselected competencies were featured for selection in the survey; however, a listing of only the top ten SEL competencies selected by respondents is listed below (see Table $1)$.

The second research question sought insight into what reported barriers to implementation, noted by each group, are perceived as preventing directly targeting SEL skills. The teaching staff group indicated that the top 3 barriers to implementation of SEL programs were lack of SEL training for teachers and staff (25.93\%), difficulty integrating/combining academic and SEL skills (24.07\%), and lack of SEL programming for the classroom (18.52\%). The administrative/leadership group noted that the top barriers to implementation were time allocation to implementation (22.6\%), lack of clarity regarding implementation

Table 1. Most important SEL competencies for students.

\begin{tabular}{ccc}
\hline & Teaching Staff & Administration \\
\hline Empathy & $20.24 \%$ & $18.82 \%$ \\
Emotional Self-Control & $11.90 \%$ & $18.82 \%$ \\
Personal Responsibility & $11.31 \%$ & $12.94 \%$ \\
Perseverance & $7.74 \%$ & $8.24 \%$ \\
Positive Self-Talk & $7.14 \%$ & $7.06 \%$ \\
Getting along well with others & $3.57 \%$ & $7.06 \%$ \\
Trust & $7.74 \%$ & $3.53 \%$ \\
Equity & $5.36 \%$ & $4.12 \%$ \\
Belonging & $5.95 \%$ & $4.12 \%$ \\
Honesty & $5.36 \%$ & $2.35 \%$ \\
\hline
\end{tabular}


(22.6\%), difficulty integrating/combining academic and SEL skills (20.8\%), and "I have not experienced any barriers regarding SEL implementation on my campus (20.8\%) (See Figure 2).

The third research question examined whom teaching and administrative staff perceive as responsible for providing direct instruction for student SEL. The two groups reported different individuals as being responsible for the direct instruction of students' SEL. The teaching staff indicated that "classroom teachers" (44\%) were responsible for it; however, only $17 \%$ of the administration group indicated that classroom teachers were responsible. The administrative group largely stated that "any individual who directly works with students" is responsible for providing that direct instruction, at $52.8 \%$. Teachers agreed; however, at a much lower rate, 35.2\% (See Figure 3).

\section{Discussion}

Research has proven that direct SEL instruction is effective in helping students improve SEL and academic success (Arslan \& Demirtas, 2016; Bridgeland et al. 2013), especially when implemented by campus staff (Bridgeland et al. 2013; Durlak et al., 2011). However, public school practitioner beliefs, understanding, and perception of SEL impact how effective these programs can be. This research sought to understand public school practitioners' beliefs and understandings of SEL along with reported barriers, and designated persons responsible for directly

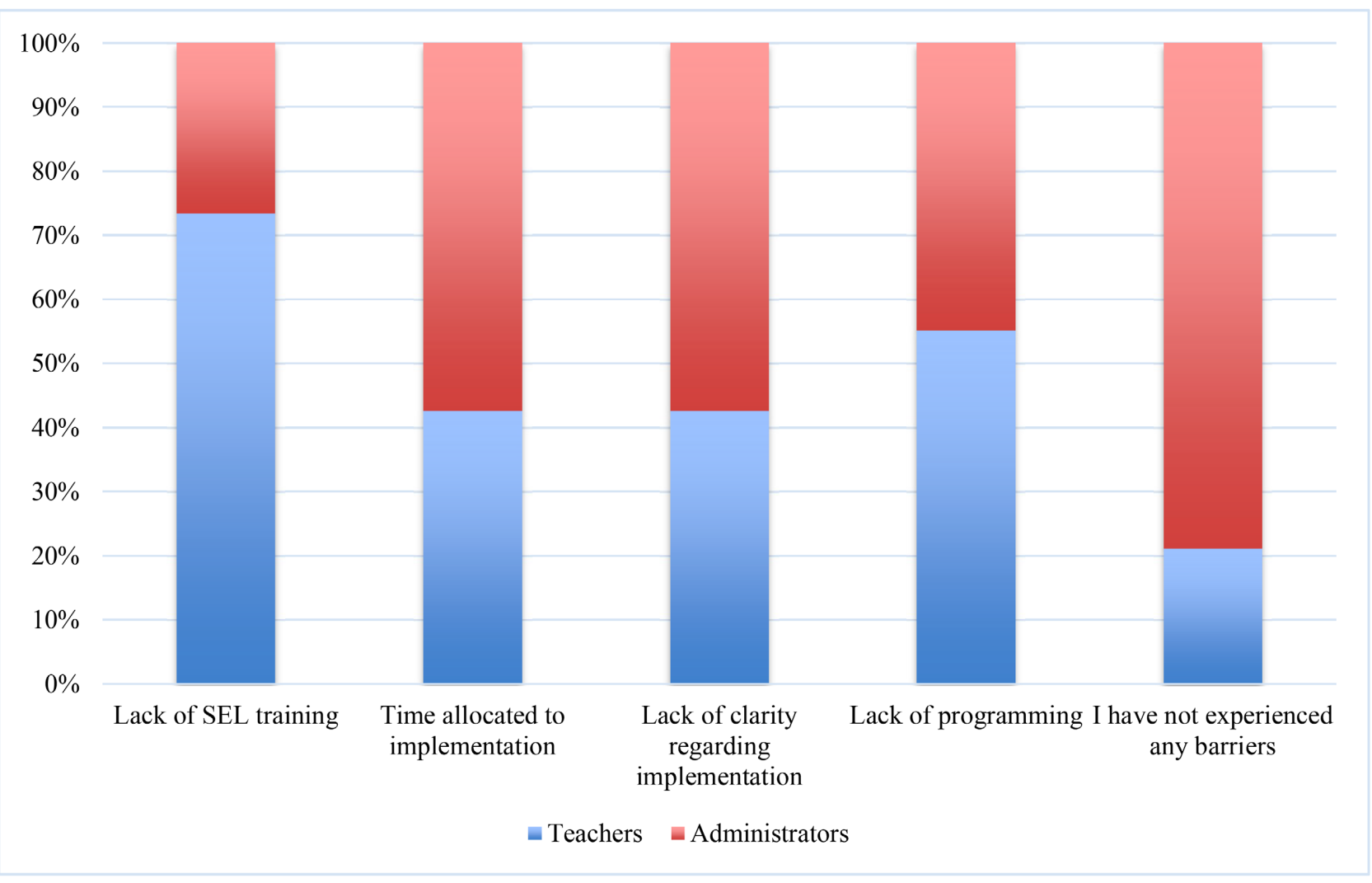

Figure 2. Participant Selected Barriers to Implementation. 


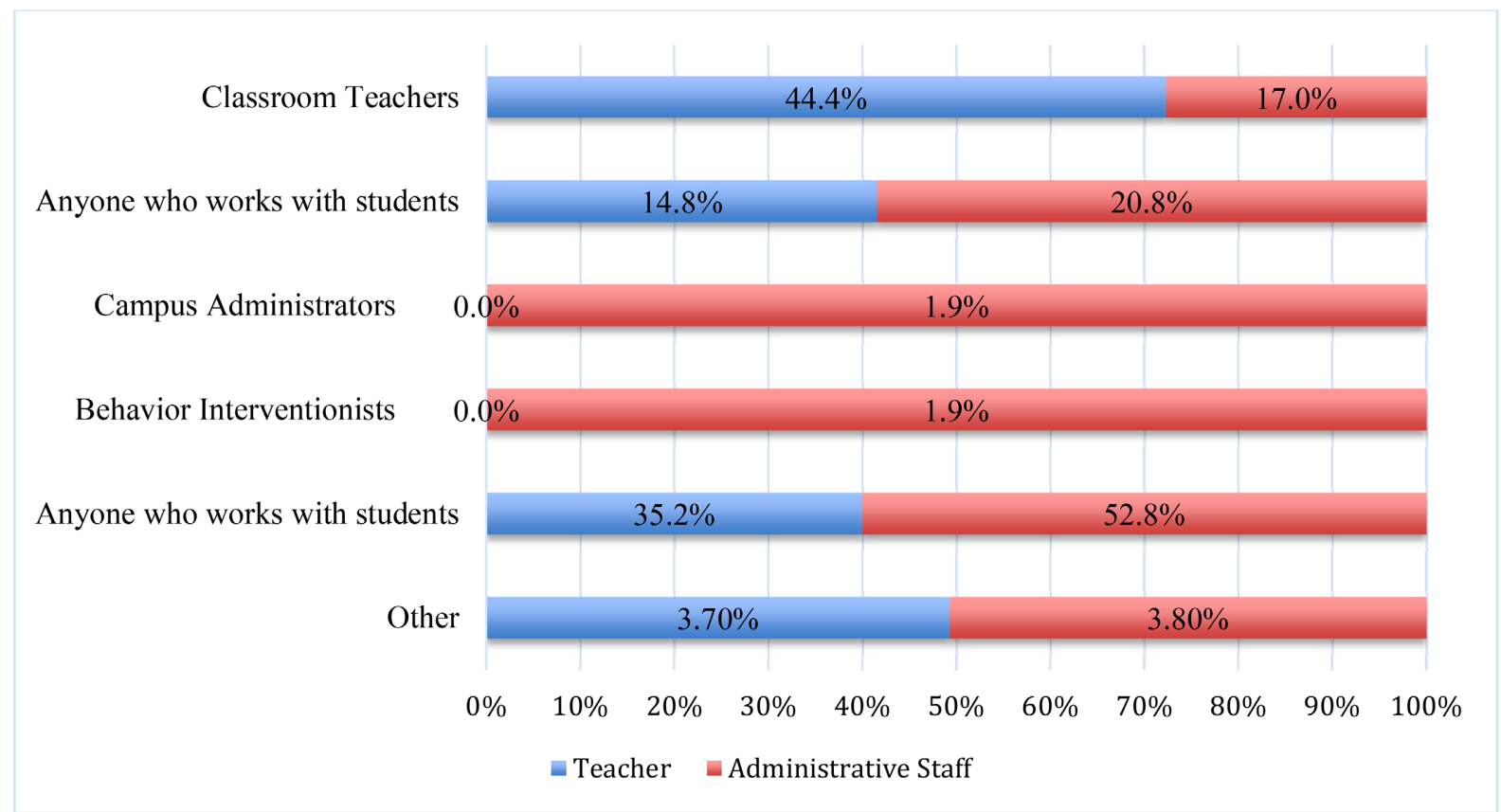

Figure 3. Responsibility for direct instruction of SEL.

teaching these skills. The study went further and examined the similarities and differences between teaching staff responses versus what was indicated by administrative/leadership staff. A non-experimental survey design was utilized to compare data between two groups of public PK-12 education practitioners: teaching and administrative staff. Overall, it was determined that educators, for the most part, agree on what SEL skills make a student successful; however, reported barriers to implementation and designation of the individual responsible for directly teaching SEL skills differed between the two groups.

\section{Research question one}

Research question one sought to understand whether classroom teachers and administrators have a shared understanding of what "SEL learning" means, and which SEL skills are most important for student success. Survey results found that almost all of the educators in both groups were able to identify the correct definition for SEL when choosing from a list. This indicates that, of the educators surveyed, a basic understanding of SEL learning is held; therefore, we may be able to conclude that the challenge educators must face is differing interpretations regarding the skills to target and how best to approach implementation and instruction in these skills (Byatzis, 2014). This was illustrated when educators were asked to rank the SEL skills that they find are the most important for student success. Even between educators, there are differing opinions as to what skills to prioritize first. Both groups ranked the same top 3 skills as most important for students: empathy, emotional self-control, and personal responsibility; however, each group differed slightly in the order of these 3 skills. Although, the top 3 skills indeed match for both groups the skills that they prioritized next are of note. Those in the teaching staff group prioritized perseverance and trust 
(tied) in $4^{\text {th }}$ and positive self-talk as $5^{\text {th }}$. Whereas the administrative staff group prioritized positive self-talk tied with getting along well with others in $4^{\text {th }}$ with goal-setting $5^{\text {th }}$. Educators and administrators may differ on which skills to target based on their role within the school community (Wahlstrom \& Louis, 2008). Educators are those interacting with the students day to day within the classroom setting, so focusing on persevering when a task is difficult, trusting others (i.e., teacher and classmates) and also being able to speak positively about themselves could impact the day-to-day functioning of the classroom significantly. Administrators who target key performance indicators (KPI) and evaluate effectiveness across various categories (i.e. attendance, discipline, college and career readiness, standardized test scores, and completion rates) may focus on SEL skills that connect directly with those outcomes (Bayle, Ozcan, \& Yildiz, 2017; Klechtermans, Piot, \& Ballet, 2011). Therefore, administrators may see getting along well with others and goal-setting as most important as it is the most relevant to the work that they do daily with students. While these discrepancies in the perceived importance of specific SEL skills are small, they can create challenges when teachers and administrators are determining which skills to prioritize and in which order. Educators' personal philosophies, backgrounds, and needs greatly influence which skill to target. The direct work they do and the role they play on the campus, or within the district, also influences which skills they feel are most important for student success. Without a shared set of targeted skills, it can be difficult to design cultural systems, programs, and direct support so that all stakeholders (students and staff alike) understand what SEL skills are being targeted, let alone how to directly teach and support those skills (Kose, 2017). All educators on campus must have a shared understanding of specific SEL skills targeted before they can design implementation programs and instruction (Taylor, Oberle, Durlak, \& Weissberg 2017; Atwell \& Bridgeland, 2019).

\section{Research question two}

Research question two looked into the reported barriers that educators cited as preventing them from directly providing instruction in and targeting SEL learning skills. Previous research has sought to understand the barriers that educators experience when it comes to implementing SEL learning on public PK-12 campuses (Durlak et al., 2011; Bridgeland et al. 2013). Educators have repeatedly demonstrated the agreed-upon importance of SEL; however, few report implementing it in their day-to-day practices (Bridgeland et al. 2013). Barriers identified have included lack of time, lack of training, and lack of clear understanding of SEL standards from the state level (Bridgeland et al. 2013; Greenberg et al., 2017). This study found that teaching staff and administrators differ on what they identified as their top barriers to implementation. The teaching staff group indicated that a lack of SEL training along with a difficulty integrating it into an already existing academic curriculum was their biggest implementation challenge. Administrative staff cited a lack of time allocated to implementation 
along with a lack of clear understanding of implementation expectations as barriers. Interestingly, many teachers in the field may argue that the administrators are those responsible for providing that clarity and prioritizing allocating the time required for the success of these SEL initiatives (Bridgeland, et al. 2013). However, administrators in the field may be waiting on clear guidance from the state and local levels to fully understand the importance they should place on SEL learning initiatives and prioritize it over other initiatives that directly target things like attendance and completion rates (Taylor, Oberle, Durlak, \& Weissberg 2017; Atwell \& Bridgeland, 2019).

\section{Research question three responses}

Lastly, this research study utilized research question three to examine whom teaching and administrative staff perceive as responsible for providing direct instruction for students' SEL learning. Often, SEL initiatives can stall or fail to thrive due to a complicated understanding of who is responsible for providing which SEL instruction and how that instruction is to be given (Atwell \& Bridgeland, 2019). Teachers, and administrators, have agreed that SEL is vital for student success; however, fewer than half report using it in their day-to-day instruction and work with students (Bridgeland et al. 2013). This research sought to determine whom educators perceive as responsible for supporting and providing direct instruction in SEL skills. From a multiple-choice list, the majority of the administrative staff group, at $52.8 \%$, indicated that they felt that any individual who works directly with students is responsible for supporting these practices and providing direct support. The teaching staff group; however, largely identified that it was classroom teachers $(44.4 \%)$ who bear the responsibility for ensuring that these skills are taught. Here a very clear and distinct divide is occurring between teaching and leadership perspectives regarding SEL learning implementation. Administrations demonstrated that they believe it is the responsibility of all campus staff; however, teachers are showing that they are still feeling like the onus of responsibility for instructing and supporting SEL learning for students lies with them. This could be due to a lack of training that targets a clear understanding for all campus personnel regarding how these programs are infused into all aspects of campus culture and practices. It could also be a result of a lack of understanding about the work that others are doing to support SEL learning instruction on the campus. Either way, more research is needed in this area to further explore how that perception of responsibility influences how SEL learning programs are being implemented on campuses and how this perception could influence the success of these programs.

\section{Limitations and Future Research}

Due to the exploratory nature of this research, some limitations were unavoidable. Non-probability convenient sampling was utilized to expedite responses. This type of sampling could have impacted the number of participants in each group and other demographic factors. Future research should seek to utilize 
identified sites through which to distribute surveys to ensure a more representative sample between the groups.

Based on the patterns and data trends identified through this study, additional research focused on comparative analysis within demographics (age ranges of educators, ethnicity, position, etc.) may also reveal the degree to which practitioner responses regarding SEL competencies and skills vary and impact the level of implementation. Moreover, this research may provide a deeper understanding of the degree to which the findings are universal to educators across the country. Future research, with expanded population size, and perhaps also including students and parents/caregivers could provide a more holistic view of directly targeting SEL competencies and skills in PK-12 public education.

Based on these findings, future research studies could take this a step further and seek to understand the confidence that educators feel in implementing these practices as well as the frequency in which they are utilizing SEL practices into their daily work. A comparison study could also be done to examine how educators are trained versus those in educational leadership roles on campuses. This information could inform the continued challenges that teachers and other public educators cite in the implementation of SEL learning practices in their everyday work and further the understanding of that integration.

\section{Implications and Conclusion}

This study investigated the beliefs, understandings, and attitudes held by educators concerning SEL learning skills. Programs and campuses that directly target SEL learning skills have proven to be effective in helping students improve social, emotional, and academic lives (Arslan \& Demirtas, 2016). The Every Student Succeeds Act (ESSA) has recognized the importance of SEL learning and encourages each school to have a plan to address improving their climate and culture (Hess, 2017). Educational leaders face a variety of challenges every day such as increased diversity and a growing emphasis on accountability measures, which has resulted in focusing time and resources more on improving academic outcomes through increased academic instruction. However, targeting SEL competencies along with academics has been proven as the most effective way to improve student success (Greenberg, Domitrovich, Weissberg, \& Durlak, 2017). With the increasing demands placed on campuses and educational leaders, educators must recognize, plan for and provide the appropriate support for targeting SEL learning to increase the probability of successful student outcomes. Many challenges have been found, researched, and cited regarding the implementation of SEL learning programs. This study found that all respondents believed that SEL and its applications are vital to educating the whole child; however, the groups differed in their opinions of which SEL skills to prioritize first. The two groups struggled to find common ground regarding who was responsible for SEL instruction teaching staff as classroom teachers vs. administrative staff citing anyone who works with students. They also differed as to their iden- 
tified barriers to implementation with the teaching staff citing lack of adequate SEL training vs. administrative staff indicating time allocated to implementation. If we are to address the implementation challenges of SEL learning programs on PK-12 campuses, we first must understand how individuals on public school campuses perceive them and how we can first find common ground. Only then will we be able to establish a firm place where we can all begin to design supports and programs that can be implemented successfully so that all students and staff can be successful academically, socially, and emotionally.

\section{Conflicts of Interest}

The authors declare no conflicts of interest regarding the publication of this paper.

\section{References}

Anyon, Y., Nicotera, N., \& Veeh, C. (2016). Contextual Influences on the Implementation of a Schoolwide Intervention to Promote Students' Social, Emotional, and Academic Learning. Children and Schools, 38, 81-87. https://doi.org/10.1093/cs/cdw008

Arslan, S., \& Demirtas, Z. (2016). Social-Emotional Learning and Critical Thinking Disposition. Studia Psychologica, 58, 276-285. https://doi.org/10.21909/sp.2016.04.723

Atwell, M., \& Bridgeland, J. (2019). Ready to Lead: A 2019 Update of Principals Perspectives on How SEL Learning Can Prepare Children and Transform Schools. A Report for CASEL.

Bailey, R., Stickle, L., Brion-Meisels, G., \& Jones, S. M. (2019). Re-Imagining Social-Emotional Learning: Findings from a Strategy-Based Approach. The Phi Delta Kappan, 100, 53-58. https://www.jstor.org/stable/26614883 https://doi.org/10.1177/0031721719827549

Bayle, A., Ozcan, K., \& Yildiz, A. (2017). Teacher Empowerment: School Administrators' Roles. Eurasian Journal of Educational Research, No. 70, 1-18. https://doi.org/10.14689/ejer.2017.70.1

Bierman, K., Coie., J., Dodge, K., Greenberg, M., Lochman, J., \& McMahon, R. (2010). The Effects of a Multiyear Universal Social-Emotional Learning Program: The Role of Student and School Characteristics. Journal of Consulting and Clinical Psychology, 78, 156-168. https://doi.org/10.1037/a0018607

Bridgeland, J.M., Bruce, M., \& Hariharan, A. (2013). The Missing Piece: A National Teacher Survey on How SEL Learning Can Empower Children and Transform Schools.

Byatzis, R. (2014). Possible Contributions to Leadership and Management from Neuroscience. Academy of Management Learning \& Education, 13, 300-303.

http://amle.aom.org/

https://doi.org/10.5465/amle.2014.0084

Cohen, J., McCabe, E., Michelli, N., \& Pickeral, T. (2009). School Climate: Research, Policy, Practice, and Teacher Education. Teachers College, 111, 180-213.

https://doi.org/10.1177/016146810911100108

Durlak, J., Weissberg, R., Dymnicki, A., Taylor, R., \& Schellinger, K. (2011). The Impact of Enhancing Students' SEL Learning: A Meta-Analysis of School Based Universal Interventions. Child Development, 82, 405-432.

https://doi.org/10.1111/j.1467-8624.2010.01564.x 
Elias, M. (2006). The Connection between Academic and Social-Emotional Learning. In M. J. Elias, \& H. A. Arnold (Eds.), The Educator's Guide to Emotional Intelligence and Academic Achievement (pp. 4-14). Corwin.

Greenberg, M., Domitrovich, C., Weissberg, R., \& Durlak, J. (2017). SEL Learning as a Public health Approach to Education. The Future of Children, 27, 13-32.

http://www.futureofchildren.org https://doi.org/10.1353/foc.2017.0001

Greenberg, M., Weissberg, R., O’Brien, R., Zins., M., Fredericks, J., Resnik, L., \& Elias, H. (2003). Enhancing School-Based Prevention and Youth Development through Coordinated Social, Emotional, and Academic Learning. American Psychologist, 58, 466-474. https://doi.org/10.1037/0003-066X.58.6-7.466

Hess, F. M. (2017). Every Student Succeeds Act. Harvard Education Press.

Jones, S. M., \& Doolittle, E. J. (2017). Social and Emotional Learning: Introducing the Issue. The Future of Children, 27, 3-11. https://doi.org/10.1353/foc.2017.0000

Klechtermans, G., Piot, L., \& Ballet, K. (2011). The Lucid Loneliness of the Gatekeeper: Exploring the Emotional Dimension in Principals' Work Lives. Oxford Review of Education, 37, 93-108. https://doi.org/10.1080/03054985.2010.545192

Kose, B. (2017). One Principal's Influence on Sustained, Systematic, and Differentiated Professional Development for Social Justice. Middle School Journal, 39, 34-42. https://doi.org/10.1080/00940771.2007.11461622

Lee, M. (2016). The Changing Nature of School Principals' Work: Lessons and Future Directions for School Leadership Research. International Studies in Educational Administration, 44, 129-135.

McBride, A., Chung, S., \& Robertson, A. (2016). Preventing Academic Disengagement through a Middle School-Based SEL Learning Program. Journal of Experimental Education, 39, 370-385. https://doi.org/10.1177/1053825916668901

Norris, J. (2003). Looking at Classroom Management through a SEL Learning Lens. Theory into Practice, 42, 313-318. https://doi.org/10.1207/s15430421tip4204 8

Payton, J., Wardlaw, D., Graczyk, P., Bloodworth, M., Tompsett, C., \& Weissberg, R. (2000). SEL Learning: A Framework for Promoting Mental Health and Reducing Risk Behavior in Children and Youth. Journal of School Health, 70, 179-185. https://doi.org/10.1111/j.1746-1561.2000.tb06468.x

Ponto, J. (2015). Understanding and Evaluating Survey Research. Journal of the Advanced Practitioner in Oncology, 6, 168-171. https://doi.org/10.6004/jadpro.2015.6.2.9

Salkind, N. (2014). Statistics for People Who (Think They) Hate Statistics. (5th ed.). SAGE Publications.

Schonert-Reichi, K. (2017). SEL Learning and Teachers. Future of Children, 27, 137-155. http://www.futureofchildren.org https://doi.org/10.1353/foc.2017.0007

Shriver, T. P., \& Weissberg, R. P. (2020). A Response to Constructive criticism of Social and Emotional Learning. Phi Delta Kappan, 101, 52-57.

https://doi.org/10.1177/0031721720917543

Smith, B. H., \& Low, S. (2013). The Role of Social-Emotional Learning in Bullying Prevention Efforts. Theory into Practice, 52, 280-287. https://doi.org/10.1080/00405841.2013.829731

Taylor, T., Oberle, E., Durlak, J., \& Weissberg, R. (2017). Promoting Positive Youth Development through School-Based SEL Learning Interventions: A Meta-Analysis of Follow-Up Effects. Child Development, 88, 1156-1171. https://doi.org/10.1111/cdev.12864 
Twenge, J. (2009). Generational Changes and Their Impact in the Classroom: Teaching Generation Me. Medical Education, 43, 398-405.

https://doi.org/10.1111/j.1365-2923.2009.03310.x

Wahlstrom, K., \& Louis, K. (2008). How Teachers Experience Principal Leadership: The Roles of Professional Community, Trust, Efficacy, and Shared Responsibility. Educational Administration Quarterly, 44, 458-495.

https://doi.org/10.1177/0013161X08321502

Yoshikawa, H., Aber, J. L., \& Beardslee, W. R. (2012). The Effects of Poverty on the Mental, Emotional, and Behavioral Health of Children and Youth: Implications for Prevention. American Psychologist, 67, 272-284. https://doi.org/10.1037/a0028015

Zins, J., \& Elias, M. (2007). SEL Learning: Promoting the Development of All Students. Journal of Educational and Psychological Consultation, 17, 233-255.

https://doi.org/10.1080/10474410701413152 